\title{
INFLUENCE OF MODULUS OF BASE LAYER ON THE STRAIN DISTRIBUTION FOR ASPHALT PAVEMENT
}

\author{
KANG YAO ${ }^{1,2,3}$, XIN JIANG ${ }^{1,2,3^{*}}$, JIN JIANG ${ }^{1,2,3}$, \\ ZHONGHAO YANG ${ }^{1,2,3}$, YANJUN QIU $1,2,3$ \\ ${ }^{1}$ School of Civil Engineering, Southwest Jiaotong University, Chengdu, China \\ ${ }^{2}$ MOE Key Laboratory of High-speed Railway Engineering, \\ Southwest Jiaotong University, Chengdu, China \\ ${ }^{3}$ Highway Engineering Key Laboratory of Sichuan Province, \\ Southwest Jiaotong University, Chengdu, China
}

Received 23 December 2020; accepted 16 March 2021

\begin{abstract}
In order to investigate the influence of modulus of the base layer on the strain distribution for asphalt pavement, the modulus ratio of the base layer and the AC layer $\left(R_{\mathrm{m}}\right)$ is introduced as a controlled variable when keeping modulus of the AC layer as a constant in this paper. Then, a three-layered pavement structure is selected as an analytical model, which consists of an AC layer with the constant modulus and a base layer with the variable modulus covering the subgrade. A three dimensional (3D) finite element model was established to estimate the strains along the horizontal and vertical direction in the AC layer under different $R_{\mathrm{m}}$. The results show that $R_{\mathrm{m}}$ will change the
\end{abstract}

* Corresponding author. E-mail: xjiang01@swjtu.edu.cn

Kang YAO (ORCID ID 0000-0003-4368-6607)

Xin JIANG (ORCID ID 0000-0002-3044-5495)

Jin JIANG (ORCID ID 0000-0001-7251-3604)

Zhonghao YANG (ORCID ID 0000-0002-6256-451X)

Yanjun QIU (ORCID ID 0000-0002-2250-5363)

Copyright (C) 2021 The Author(s). Published by RTU Press

This is an Open Access article distributed under the terms of the Creative Commons Attribution License (http://creativecommons.org/licenses/by/4.0/), which permits unrestricted use,

distribution, and reproduction in any medium, provided the original author and source are credited. 
distribution of the horizontal strains along the depth in the AC layer; the increase of $R_{\mathrm{m}}$ could reduce the maximum tensile strain in the AC layer, but its effect is limited; the maximum tensile strain in the AC layer does not necessarily occur at the bottom, but gradually rises to the middle with the increase of $R_{\mathrm{m}}$. $R_{\mathrm{m}}$ could significantly decline the bottom strain in the AC layer, and there is a certain difference between the bottom and the maximum strain when $R_{\mathrm{m}}$ is greater than or equal to one, which will enlarge with increasing $R_{\mathrm{m}} . R_{\mathrm{m}}$ could change the depth of the neutral axis in the AC layer, and the second neutral axis will appear at the bottom of the AC layer under a sufficiently large $R_{\mathrm{m}}$. The average vertical compressive strain in the AC layer will significantly enlarge with the increase of $R_{\mathrm{m}}$.

Keywords: Asphalt pavement, elastic modulus, Finite Element Method, mechanical response, neutral axis.

\section{Introduction}

Being one of the mainstream construction materials for the surface layer of the pavement structure, asphalt concrete (AC) has many apparent advantages, including capability to ensure great driving comfort, excellent skid resistance and ease of construction, which at present makes asphalt pavement structures ubiquitous around the world (Huang, 2004). On the other hand, in order to withstand severe climate, environmental and traffic conditions in different regions, a variety of materials are also introduced in the asphalt pavement as the base layer to further improve the bearing capacity of the entire pavement structure. Depending on different levels of stiffness of base layer materials, asphalt pavement structures can be grouped into three types, i.e., flexible base pavement structures, semi-rigid base pavement structures, and rigid base pavement structures (Huang, 2017). Specifically, granular materials or asphalt stabilized materials, chemically stabilized materials, and cement concrete or other materials with high stiffness were chosen as the base layer for flexible, semirigid and rigid base pavement structure, respectively. Considering the modulus of the base in diverse pavement structures, a large number of previous research papers (Saad et al., 2006; Hu \& Walubita, 2011; Xiao et al., 2011; Francois et al., 2019) have shown that the pavement structures with the base with high modulus demonstrate different mechanical properties as compared to those with the base with low modulus, which will affect the service capacity of the structures. Hence, it is necessary to discuss the influence of the modulus of the base layer on the mechanical behavior of the pavement structure.

Within the Mechanical-Empirical (M-E) design procedure, each layer of the pavement structure will be given a constant modulus
Yanjun Qiu

Influence of Modulus

of Base Layer

on the Strain

Distribution

for Asphalt

Pavement 
so that it could be applied to obtain mechanical response under wheel loading with other parameters, such as layer thickness and Poisson's ratio. However, many objective factors and their strong mutual interaction occurring during and/or after the construction will result in the decrease of the modulus of the base layer and the AC layer, resulting in detrimental effects on the construction quality and environmental effects (Collop \& Cebon, 1995 \& 1996; Benedetto et al., 2004; Lv et al., $2018 \& 2019$ ). It is clear that it is difficult to keep the moduli of the base and AC layer at a fixed value during a long-term service life, and the changes in the modulus will affect the performance of the pavement structure. Therefore, in order to consider and control the impact of the modulus of the AC layer, it is appropriate to introduce the modulus ratio of the base layer and the AC layer $\left(R_{\mathrm{m}}\right)$ as a controlled variable in the research of the influence of the modulus of the base layer on mechanical behavior of the asphalt pavement.

Besides, the AC layer at the surface of the pavement structure is influenced by the natural environment and repeated vehicle loading. Along with the increase of the service time, the AC layer will deteriorate and finally many diseases will develop under the impact of many factors, which will eventually lead to the need to repair or rebuilt the pavement structure (Collop \& Cebon 1995; Huang 2004). The main types of diseases that may occur in the AC layer, including fatigue cracking, top-down cracking and permanent deformation, are considered to be closely related to the strain distribution in the AC layer. For example, the horizontal strain is usually used to control the fatigue cracking and topdown cracking of the AC layer, and the vertical strain is used to predict the permanent deformation of the AC layer (Applied Research Associates, Inc., 2004a). Therefore, it is necessary to consider the influence of the modulus of the base layer on the strain distribution in the asphalt pavement structure.

As a result, a three-layered pavement structure has been selected as analytical example in this paper, the structure consists of an AC layer with constant modulus and a base layer with variable modulus covering the subgrade. The above pavement structure was designed to consider a larger range of modulus of the base layer due to different materials that were used in construction thereof. Then, a three dimensional (3D) finite element model developed from EverStressFE (Davids, 2009) was used to compute and investigate the critical strains along both horizontal and vertical directions in the AC layer of the selected pavement structure under different $R_{\mathrm{m}}$. 


\section{Review of the distribution range of modulus of the base layer for different materials}

It is apparent that in the practical engineering situations, the base layer of the asphalt pavement structure can be constructed using various materials with different stiffness. The representative materials include granular materials, chemically stabilized materials, cement concrete and recycled materials, including reclaimed asphalt pavement (RAP), recycled construction and demolition waste, reclaimed concrete aggregate and so on. A large number of experiment-based material studies conducted by researchers (Mohammad et al., 2000; Camargo, 2008; Solanki et al., 2009; Cetin et al., 2010; Leite et al. 2011; Bilodeau \& Doré, 2012; Jiang \& Fan, 2013; Arulrajah et al., 2015; Bestgen et al., 2016; Miao et al., 2016; Arshad, 2018; Li et al., 2019; Ji et al., 2019; Romeo et al., 2019; Bassim \& Issa, 2020) during the last years have shown the all materials mentioned above demonstrate different mechanical properties in pavement structure, including the modulus which is usually employed to represent the stiffness of material, in particular. As a result of these

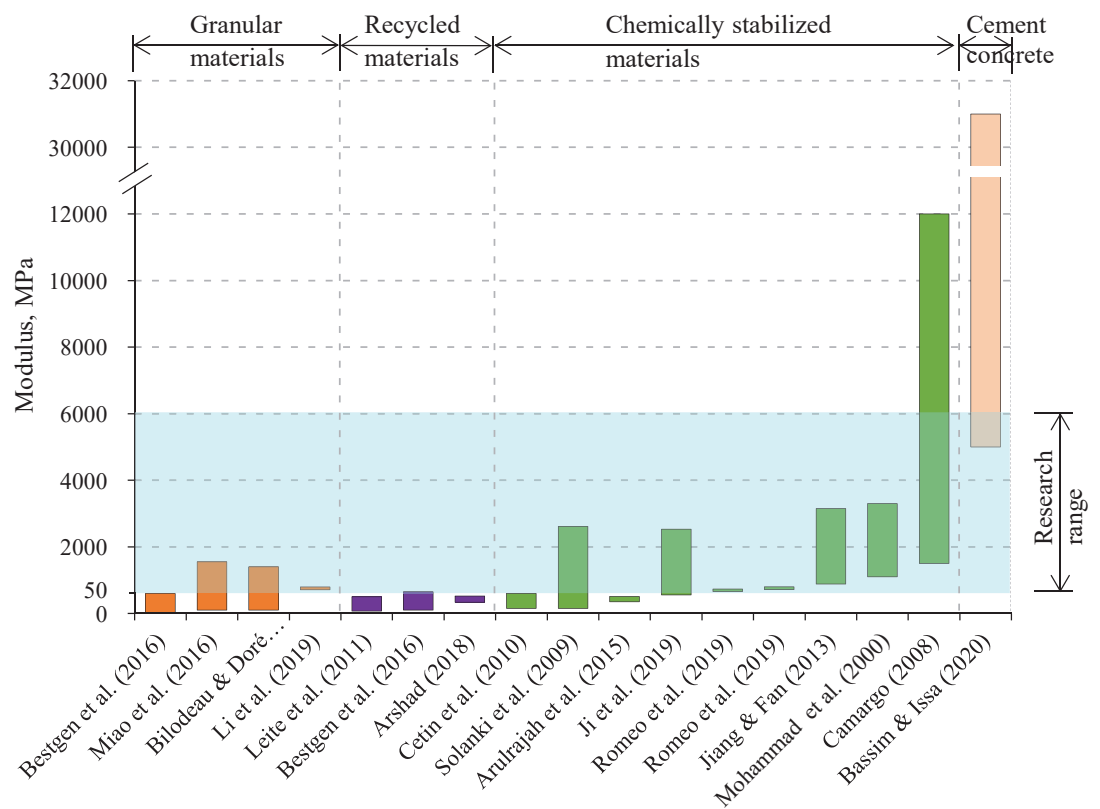

Figure 1. The modulus range of different materials of the base layer
Yanjun Qiu

Influence of Modulus

of Base Layer

on the Strain

Distribution

for Asphalt

Pavement 
developments, the distribution range of modulus for four kinds of typical materials used to construct the base layer is summarized as shown in Figure 1. It clearly implies that the variation range of modulus of these materials is extremely wide, ranging from $30 \mathrm{MPa}$ (granular materials) to $31000 \mathrm{MPa}$ (cement concrete). As it may in Figure 1, the modulus of cement concrete generally is the largest, followed by that of chemically stabilized materials and granular materials, and that of recycled material is the smallest due to some existing damage that could have occurred before recycling, such as cracks and permanent deformation. Besides, even in the same kind of material, there may be a great difference in its modulus, because modulus is affected by many factors, such as gradation, humidity, additive content, repetitions of loading, etc. For instance, the minimum modulus of chemically stabilized materials is $150 \mathrm{MPa}$, meanwhile its maximum modulus is $12000 \mathrm{MPa}$ based on the existing experimental results.

In conclusion, the material of the base layer has a large range of modulus, which will inevitably affect the performance of the AC layer. Therefore, the influence of the modulus of the base layer on the mechanical behavior (in particular, strain distribution) of the AC layer is emphasized again in this study. In other words, the reasonable matching of the modulus between the base layer and the AC layer requires more attention. In order to cover all the representative materials of the base layer as comprehensively as possible, the researched modulus range of 500 6000 MPa has been adopted for the following analysis conducted in the paper.

\section{Establishment and validation of the finite element model}

EverStressFE was selected to design a 3D finite element model to calculate the critical strain distribution in the AC layer. Developed by the University of Maine with financial support from the Washington State Department of Transportation, this software package with user-friendly graphical user interface (GUI) could effectively save time for model generation, calculation and post-processing due to the capability of some outstanding features, including automated meshing, coupling of finite element and infinite element and so on (Clapp, 2007; David, 2009; Henry et al., 2009; Abdelfattah et al., 2018; Jiang et al., 2019 \& 2021). Therefore, it is employed extensively in 
the mechanical analysis of asphalt pavement structure in terms of Influence of Modulus displacement, stress and strain.

\subsection{Loading condition}

on the Strain

Distribution

for Asphalt

Pavement

The $100 \mathrm{kN}$ single axle with dual tires, which is treated as a vertical distributed circular uniform load, is assumed to act on the surface of the pavement structure. The tire-pavement contact pressure is $700 \mathrm{kPa}$, the radius of the loading zone is $107 \mathrm{~mm}$, and the distance of the dual tires is $320 \mathrm{~mm}$.

\subsection{Pavement structure and materials properties}

A typical three-layered pavement structure composed of an AC layer with a thickness of $200 \mathrm{~mm}$ and a base layer of $300 \mathrm{~mm}$ covering the subgrade has been chosen here as an object for analysis, as shown in Figure 2(a). To provide for parallel comparison, all layers in the above-mentioned pavement structure are regarded as linear elastic bodies, which is a relatively valid assumption to reveal the influence of modulus of the base layer on the strain distribution in the AC layer in this case study. The mechanical parameters of the pavement materials, including elastic modulus and Poisson's ratio, are given in Figure 2(a) based on the assumption of linear elasticity. It should be noted that the modulus range of the base layer is large due to different material properties, but the modulus of the AC layer has a relatively little variation in many types of pavement structure. It is worth mentioning that the modulus of the AC layer under $15 \sim 35^{\circ} \mathrm{C}$ is usually used in pavement structure design in many countries (IRC, 2012; Corté \& Goux, 1996; AASHTO, 1993; Ministry of Transport of China, 2006; Austroads, 2017). Consequently, a typical constant value of $2000 \mathrm{MPa}$ was defined as the modulus of the AC layer under the specified temperature range based on the previous studies reflecting on results of laboratory tests (Austroads, 2017; Brown \& Foo, 1991; Fakhri \& Ghanizadeh, 2014; IRC, 2012; Lavasani et al., 2015; Ministry of Transport of China, 2006; Shafabakhsh \& Tanakizadeh, 2016; Venudharan \& Biligiri, 2015). At the same time, the modulus of the base layer was considered as a variable ranging from $500 \mathrm{MPa}$ to 6000 MPa according to the findings presented in Section 1, that is to say, $R_{\mathrm{m}}$ is distributed in a range from 0.25 to 3 . Besides, the base layer with different modulus was supposed to have its corresponding different Poisson's ratio. For example, the Poisson's ratio of soft materials, e.g., 
granular materials, is about $0.35 \sim 0.4$, and that of stiff materials, e.g., cement concrete, is about $0.2 \sim 0.25$. However, the Poisson's ratio has little impact on the mechanical responses of the asphalt pavement structure (Schwartz et al., 2013). Therefore, for the convenience of calculation, the average value of Poisson's ratio of 0.3 was adopted in this paper.

\subsection{Geometric dimensions of the model and boundary conditions}

Considering the characteristics of EverStressFE software and the symmetry of the finite element model, a $1 / 4$ model was selected to simplify the computing process, as shown in Figure 2(a). Figure 2(b) shows that the model selected in the program consists of the finite element domain and the infinite element domain; the ordinary 20-node cubic elements were utilized in the finite element domain to discretize the model, while the infinite elements were introduced in the infinite element domain to diminish the number of far-field elements without significant loss of computing accuracy and to provide the boundary conditions except the two symmetric surfaces.

In order to define the location of the infinite boundaries at both horizontal sides and the bottom of the finite element model, Al-Qadi et al. (2008) performed a sensitive analysis and then compared the critical mechanical responses, including the strains along the transverse and driving direction at the bottom of the AC layer and the maximum compressive stress at the top of the subgrade, with the full-size finite element model ( $3 \mathrm{~m} \times 3 \mathrm{~m} \times 5 \mathrm{~m})$. It was demonstrated that the accurate solution could be obtained using the horizontal location of the infinite boundary from the load center greater than $900 \mathrm{~mm}$ and the location of the bottom infinite boundary at a depth of $1100 \mathrm{~mm}$. Applied Research Associates, Inc. (2004b) also suggested that the infinite boundaries should be set at 760 to $1200 \mathrm{~mm}$ away from the center of the load. Clapp (2007) recommended that the dimensions of the finite element domain are equal to ten times the radius of the applied wheel load. Based on the research results mentioned above, in order to minimize the adverse effects induced by the boundary considering the loading condition illustrated in Section 2.1, both dimensions of the driving and transverse direction for the finite element model were all set at $1100 \mathrm{~mm}$ away from the center of the dual tires, and the bottom infinite boundary was set at a depth of $1100 \mathrm{~mm}$ away from the surface of the pavement structure considered in this study, as shown in Figure 2(b). 


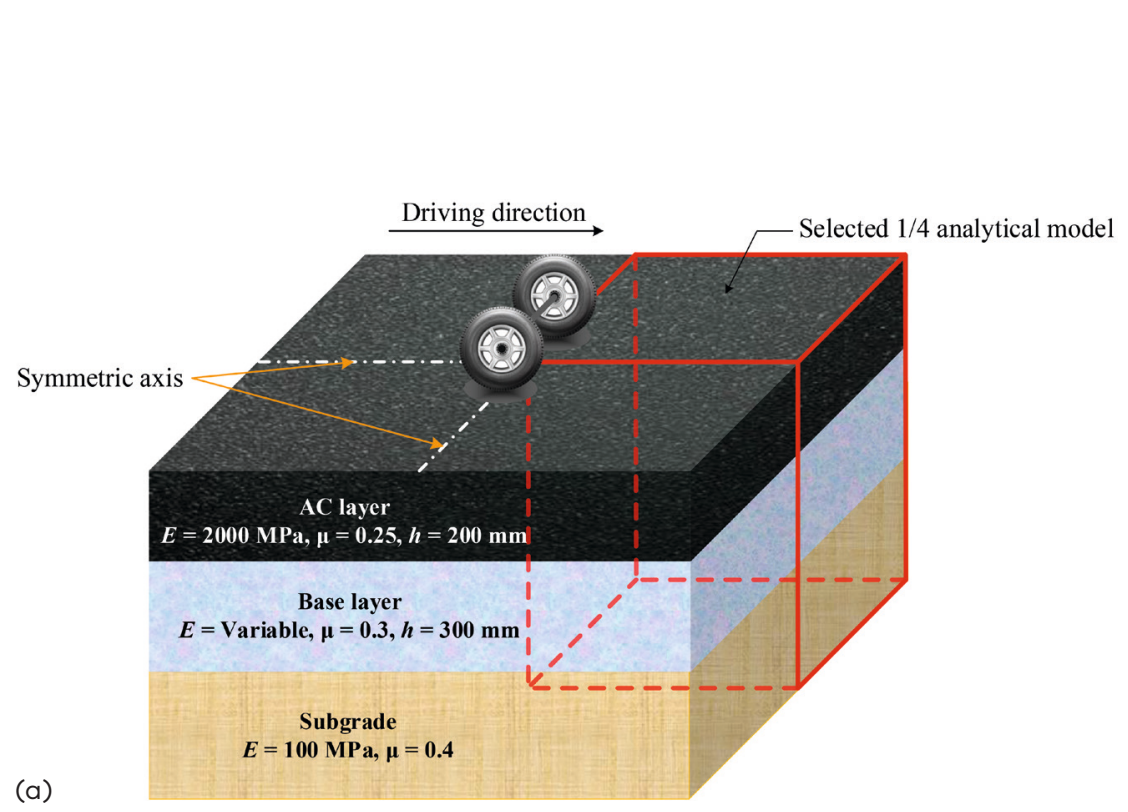

Kang Yao,

Xin Jiang, Jin Jiang,

Zhonghao Yang,

Yanjun Qiu

Influence of Modulus

of Base Layer

on the Strain

Distribution

for Asphalt

Pavement

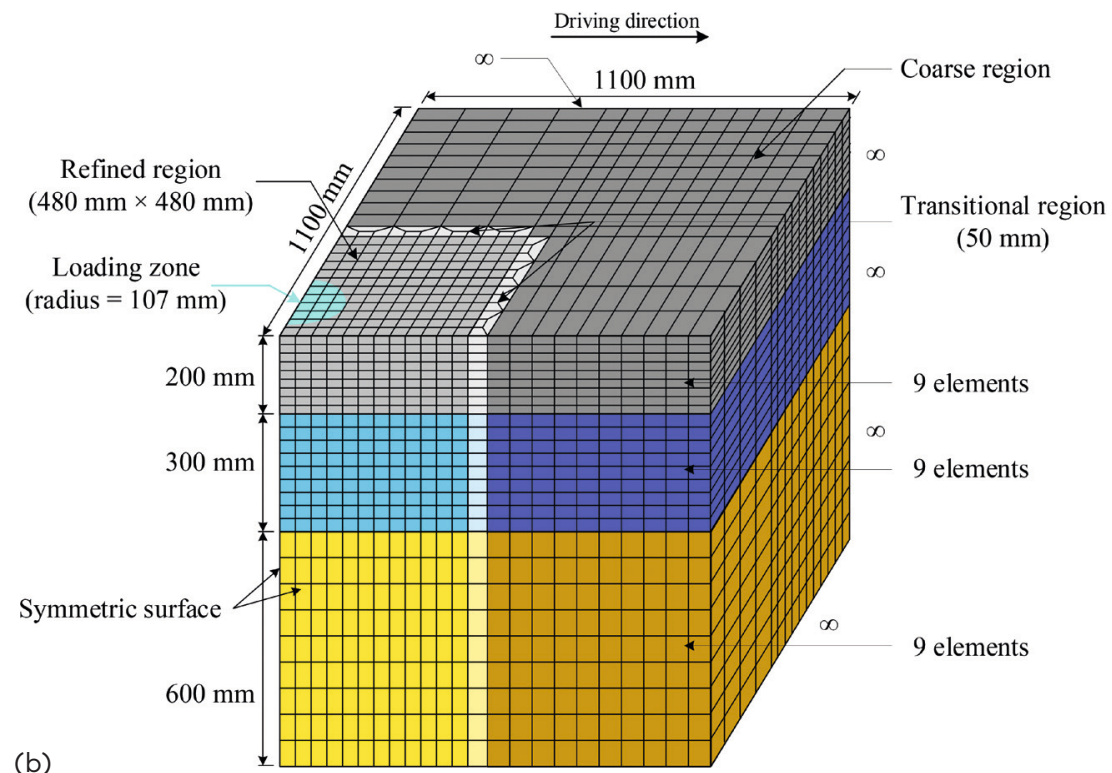

Note: $\infty$ is defined as the infinite boundary here

Figure 2. The finite element model: (a) selected $1 / 4$ model, (b) geometric dimensions and mesh 


\subsection{Mesh of the finite element model}

The model comprised a refined mesh around the loading zone, a relatively coarse mesh at a distance from the loading zone, and a transitional region between the refined region and the coarse region, as shown in Figure 2(b). In the horizontal directions, Clapp (2007) recommends that the in-plane dimensions of the locally refined region are taken as three times the radius of the applied load and at least 9 element divisions along both horizontal directions should be used here if accurate solutions are required for the base layer and the AC layer. Consequently, in this paper, the in-plane dimension of the refined region is set at $480 \mathrm{~mm} \times 480 \mathrm{~mm}$, which is equally divided into 12 elements along the driving and transverse directions. And the coarse region is equally divided into 10 elements along the driving and transverse directions. Meanwhile, the transitional region from the refined to coarse region is defaulted at $50 \mathrm{~mm}$. In the vertical direction, all elements have identical vertical dimension in each layer in the program. Moreover, Clapp (2007) also suggests that 2, 4 and 6 elements divisions should be taken in the AC layer, base layer, and subgrade through the thickness of the layer, respectively, and increasing the number of element divisions through the thickness of each layer has a little effect on the

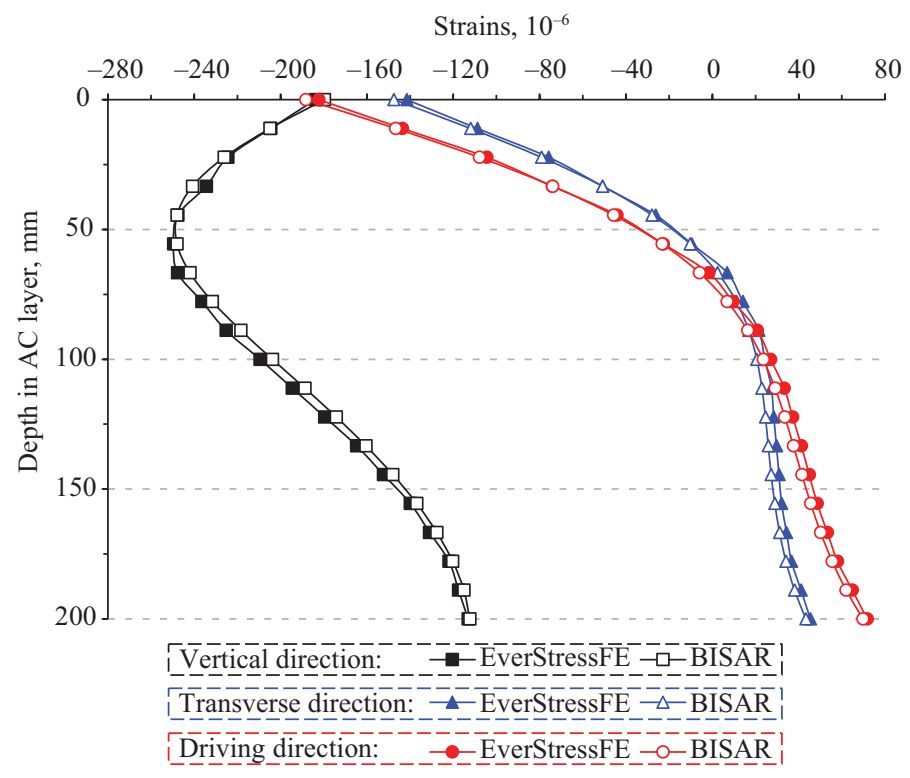

Figure 3. Results of comparison between EverStressFE and BISAR 
final solutions. Therefore, divisions into 9 elements are determined in each layer to ensure higher accuracy in this paper. In addition, fully continuous interlayer bonding condition was assumed between the AC layer and the base layer, as well as the base layer and the subgrade, in the pavement structure.

In summary, the final finite element model was divided into 10179 20-node cubic elements with a total of 45056 nodes, as demonstrated in Figure 2(b).

\subsection{Verification of the finite element model}

In order to validate the correctness of the finite element model established above, a linear elastic layered system program BISAR (Bitumen Business Group, 1998), well-known in the field of pavement, was adopted here to compare the calculated results. The pavement structure shown in Figure 2 with the base layer modulus of $1000 \mathrm{MPa}$ was used in both programs. The distribution of strains along the driving, transverse and vertical directions in the AC layer was obtained by both programs under the center of one of the dual tires, as shown in Figure 3. It could be seen that the distributions of the critical strains calculated by the two programs are in good agreement from the macro rule to specific value. It has been fully confirmed that the finite element model established above is extremely reliable, which provides a solid foundation for the following analysis.

\section{Discussion of results}

First of all, a large number of previous studies (Park \& Lytton, 2004; Al-Hadidy \& Tan, 2009; Huang et al., 2011; Abu Al-Rub et al., 2012; Cortes et al., 2012; Maina et al., 2012; Liu \& Shalaby, 2013; Aarabi \& Tabatabaei, 2018; Li \& Hao, 2020) indicated that the maximum critical strains in the AC layer always appears under the loading zone, so the in-plane coordinate of the calculated point used in the following analysis in this paper is located at the center of one of the dual tires.

\subsection{Distribution of critical strains along depth in AC layer}

Figure 4 shows the distribution of the critical strains along the depth in the AC layer under different $R_{\mathrm{m}}$. In both horizontal directions, it could be seen that when the value of $R_{\mathrm{m}}$ is small, the maximum tensile strains appear at the bottom of the $\mathrm{AC}$ layer, and therefore the
Influence of Modulus

of Base Layer

on the Strain

Distribution

for Asphalt

Pavement 
(a)

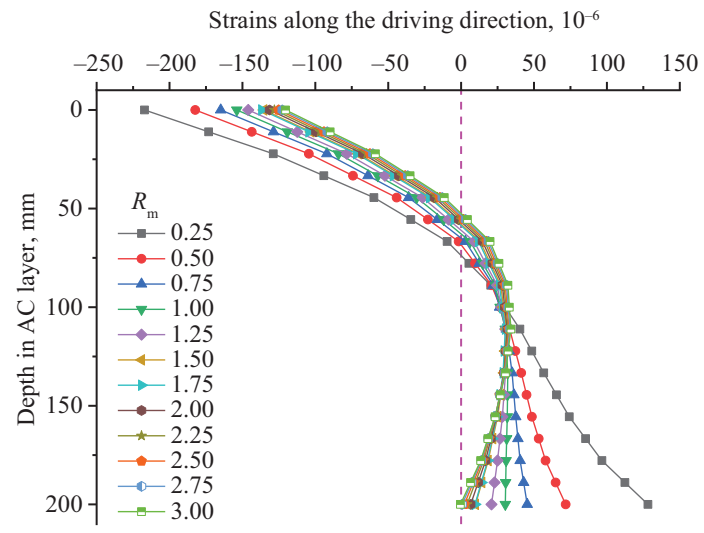

Strains along the transverse direction, $10^{-6}$

(b)

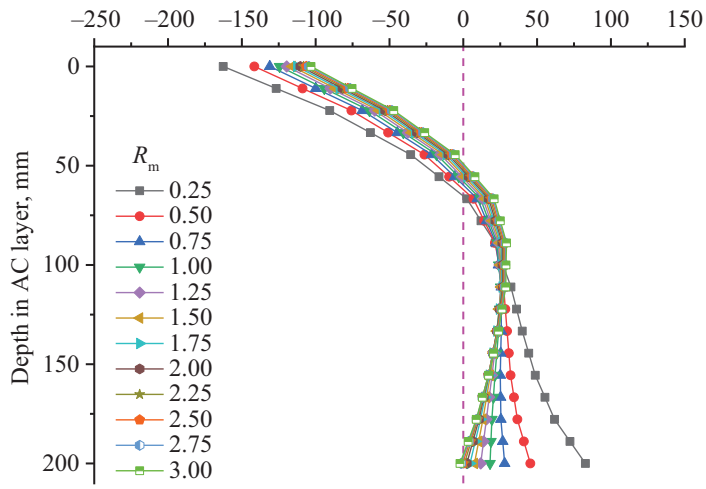

(c)

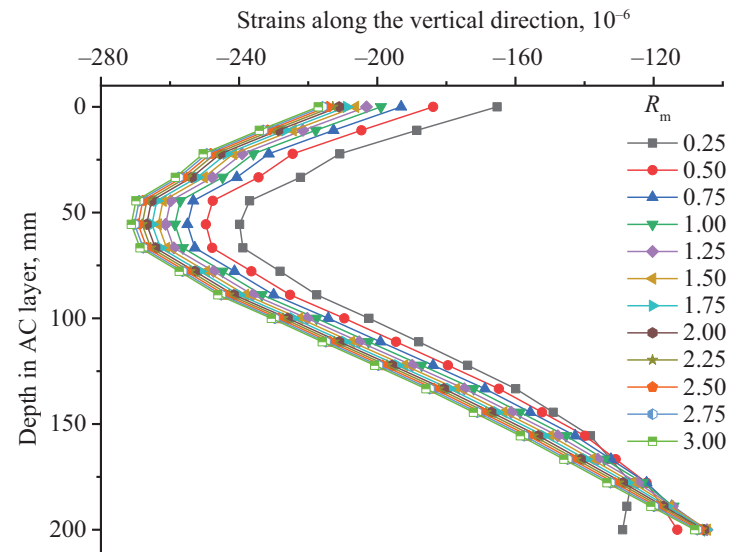

Figure 4. Distribution of critical strains along the depth in the AC layer: (a) strains along the driving direction, (b) strains along the transverse direction, (c) strains along the vertical direction 
fatigue cracking of the AC layer may first occur in this zone. Besides, with the increase of the $R_{\mathrm{m}}$ value, the tensile strains at the bottom of the AC layer will decrease sharply. When $R_{\mathrm{m}}$ is equal to two, the tensile strain values along both horizontal directions are even close to zero. Although the growth of $R_{\mathrm{m}}$ could successfully reduce the magnitude of horizontal tensile strains at the bottom of the AC layer, its effect is limited. When $R_{\mathrm{m}}$ continues increasing, the value of the bottom tensile strains along both horizontal directions will decline slowly. In addition, the horizontal compressive strains appear in the upper part of the AC layer and diminish along the depth under a small $R_{\mathrm{m}}$. Then, the compressive strain will transform into the tensile strain in the middle of the AC layer, and the value of the tensile strain will increase along the depth. With the increase of $R_{\mathrm{m}}$, the horizontal compressive strain is still located in the upper part of the AC layer, but after the compressive strain is converted into the tensile strain in the middle of the AC layer, the increased rate of the tensile strain along the depth will become slow. When $R_{\mathrm{m}}$ is large enough, the value of the tensile strain even decreases along the depth, which indicates that when $R_{\mathrm{m}}$ exceeds a certain value, the maximum horizontal strain will appear inside the AC layer rather than at its bottom.

In the vertical direction, the strain in the AC layer always is compressive. The vertical compressive strain initially increases and finally decreases along the depth in the AC layer, and the maximum value of that is located at about $55 \mathrm{~mm}$ away from the surface of the pavement structure. Moreover, with the increase of $R_{\mathrm{m}}$, the compressive strain

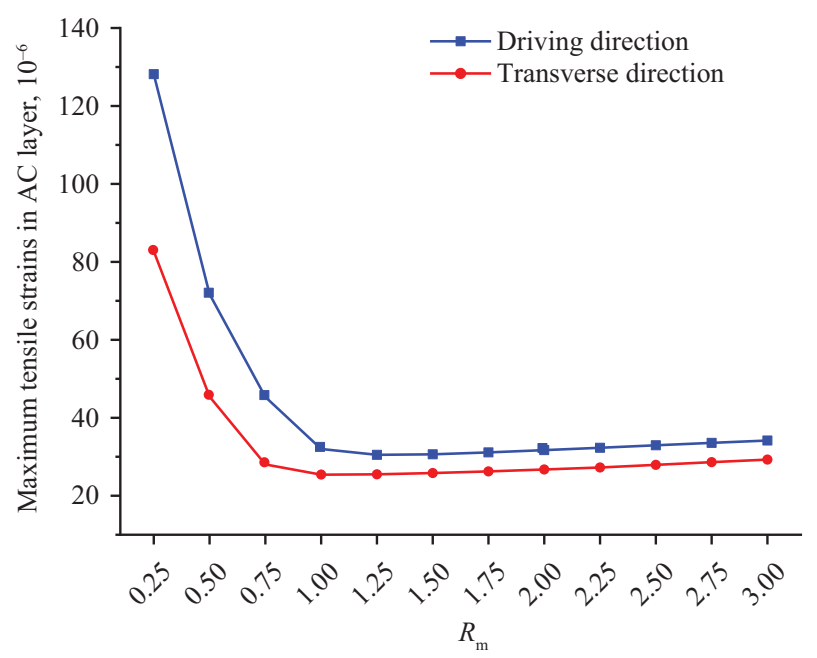

Figure 5. The maximum tensile strains in the AC layer
Influence of Modulus

of Base Layer

on the Strain

Distribution

for Asphalt

Pavement 


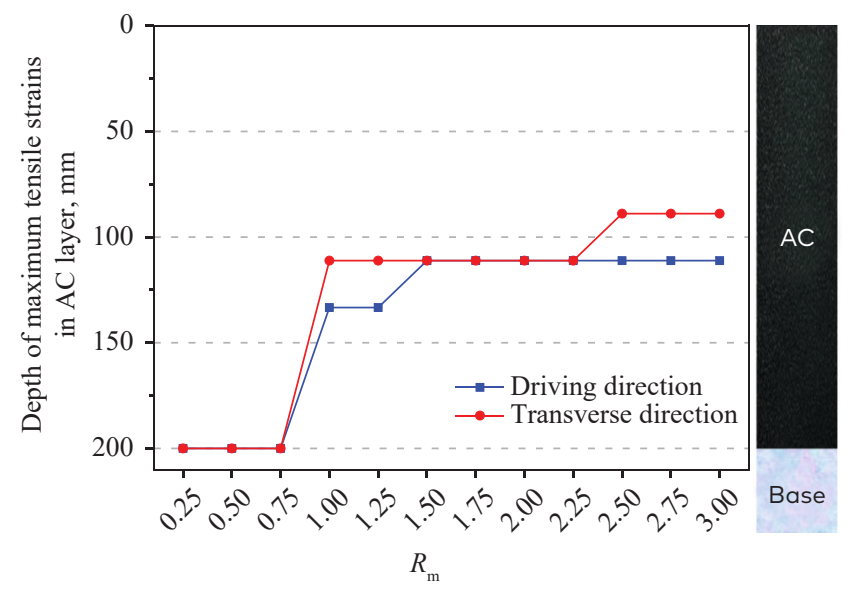

Figure 6. Depth of the maximum horizontal strains in the AC layer

value in the whole AC layer demonstrates a trend for growth, but that in the lower part of the layer will decrease.

The above presented rules allow concluding that $R_{\mathrm{m}}$ has a great influence on all critical strains of the AC layer. Therefore, within the framework of this research, the maximum tensile horizontal strains in the AC layer and their location, the comparison of horizontal maximum and bottom strains in the $\mathrm{AC}$ layer, the tensile, compressive zone and neutral axis in the AC layer, and the average vertical compressive strain in the AC layer are discussed in detail below.

\subsection{Maximum horizontal tensile strains in the AC layer}

Figure 5 presents the maximum horizontal tensile strain along the driving and transverse directions in the AC layer under different $R_{\mathrm{m}}$. The figure illustrates that the maximum tensile strain along the driving direction is always greater than that along the transverse direction, which is independent of $R_{\mathrm{m}}$. The phenomenon points at the fact that the maximum tensile strain along the driving direction is the main reason inducing fatigue cracking in the $\mathrm{AC}$ layer. In addition, the maximum tensile strain in the AC layer initially could be reduced with the rise of $R_{\mathrm{m}}$, but when the value of $R_{\mathrm{m}}$ is greater than 1 , that is, when the modulus of the base layer is greater than that of the AC layer, the tensile strain will increase slightly. Thus, it may be concluded that when the modulus of the base layer is lower than that of the AC layer, properly increasing $R_{\mathrm{m}}$ could excellently minimize the maximum tensile strain in the AC layer 
with the intention of controlling the fatigue cracking, but in the opposite Influence of Modulus case, the alteration of $R_{\mathrm{m}}$ has little impact on the maximum tensile strain value.

Figure 6 presents the depth of the maximum tensile strain in the AC of Base Layer on the Strain Distribution for Asphalt Pavement layer under different $R_{\mathrm{m}}$, which proves that when $R_{\mathrm{m}}$ is less than one, that is, when the modulus of the base layer is less than that of the AC layer, the depth of the maximum horizontal strain is always located at the bottom of the AC layer. However, when $R_{\mathrm{m}}$ is greater than one, that is, when the modulus of the base layer is greater than that of the AC layer, the location of the maximum horizontal tensile strain begins to rise to the middle of the AC layer, and this trend will maintain with increasing $R_{\mathrm{m}}$. This indicates that amplifying $R_{\mathrm{m}}$, the maximum tensile strain in the AC layer does not necessarily occur at the bottom of the AC layer, but gradually rises to the middle of the AC layer, which may even induce initial cracking in the middle of the AC layer. Besides, by comparing both horizontal directions, it could be observed that the depth of the maximum strain along the transverse direction rises faster than that along the driving direction along with the increase of $R_{\mathrm{m}}$.

\subsection{Comparison of the horizontal maximum and bottom strains in the AC layer}

The aforementioned results show that with the increase of $R_{\mathrm{m}}$, the depth of the maximum horizontal strain in the AC layer will gradually rise from the bottom to the middle of the AC layer. However, since in this paper, the horizontal tensile strain at the bottom of the AC layer has been selected to predict the potential fatigue cracking in the AC layer within the current design method of the pavement structure (Applied Research Associates, Inc. 2004a), the horizontal maximum strain and bottom strain of the AC layer are compared under different $R_{\mathrm{m}}$, as shown in Figure 7. The figure allows concluding that the tensile strain at the bottom of the AC layer will decrease with the increase of $R_{\mathrm{m}}$, but the rate of decrease will gradually slow down. When $R_{\mathrm{m}}$ is defined as a sufficiently large value, compressive strain occurs even at the bottom of the AC layer. Specifically, when $R_{\mathrm{m}}$ is about 2.5 , the compressive strain at the bottom of the AC layer initially appears in the transverse direction. Then, when $R_{\mathrm{m}}$ is about 3.0, the compressive strain at the bottom of the AC layer will occur in both driving and transverse directions. This discovery denotes that the increase of $R_{\mathrm{m}}$ could greatly reduce the tensile strain at the bottom of the AC layer, which is finally converted to the compressive strain. 
(a)

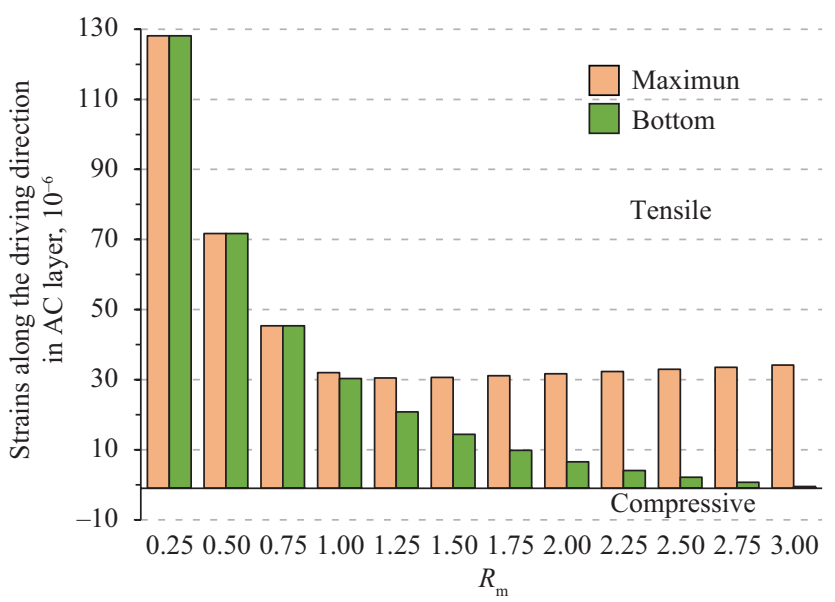

(b)

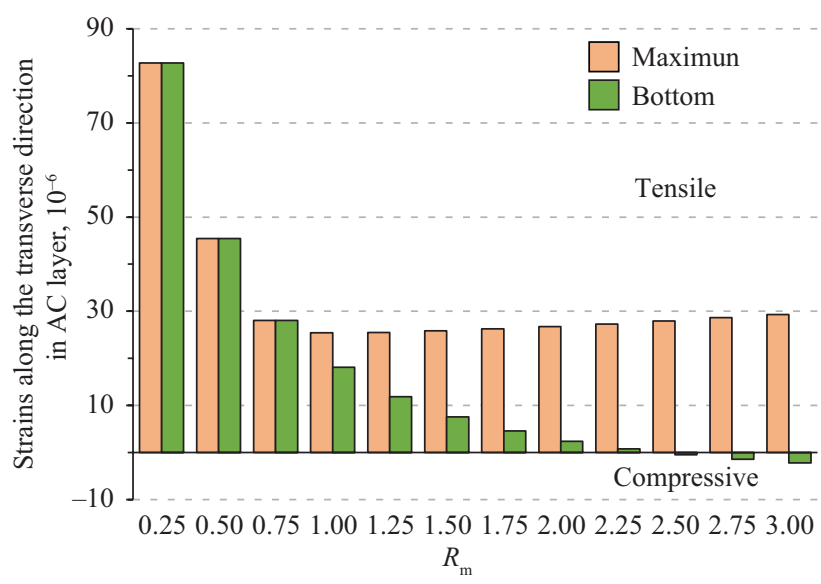

Figure 7. The horizontal maximum and bottom strains of the $A C$ layer: (a) along the driving direction, (b) along the transverse direction

Besides, when $R_{\mathrm{m}}$ of the base layer and the AC layer is greater than or equal to one, there is a certain difference between the bottom strain and the maximum strain, which will enlarge with increasing of $R_{\mathrm{m}}$. This indicates that if the tensile strain at the bottom of the AC layer, instead of the maximum tensile strain, is still used to predict the fatigue cracking of the $\mathrm{AC}$ layer when the $R_{\mathrm{m}}$ is larger than or equal to one, the fatigue life of the pavement structure will be significantly overestimated. Therefore, in this case, the engineer should consider that the maximum tensile strain will occur in the middle of the AC layer and use it to predict the fatigue cracking of the $\mathrm{AC}$ layer. 


\subsection{Tensile, compressive zone and neutral axis in the AC layer}

The contour graphics in the refined region around vehicle tires have been drawn to illustrate the strains occurring along the horizontal directions in the AC layer with $R_{\mathrm{m}}=0.25$ and 3 , as shown in Figure 8 . It is demonstrated that the maximum strain along both horizontal directions is located at the bottom of the asphalt layer with $R_{\mathrm{m}}=0.25$ and in the middle of the asphalt layer with $R_{\mathrm{m}}=3$, respectively. The tensile strain along the transverse direction would occur at the surface of the pavement structure. Since the neutral axis in the AC layer is no longer a straight line, and it is inconvenient to divide the whole AC layer into the upper and lower part based on the tensile and compressive zone for design improvement purposes, strain distribution under the center of a single tire, where the maximum strains are located, was selected for further study.

Figure 9 demonstrates the distribution of the tensile, compressive zone and the depth of the neutral axis in the AC layer along the driving and the transverse direction under the center of a single tire with different $R_{\mathrm{m}}$. It has been illustrated that the upper part of the AC layer is compressive in both directions, the lower part of the AC layer is tensile, and the neutral axis is located at about $50 \sim 80 \mathrm{~mm}$ away from the surface of the pavement structure. With the increase of $R_{\mathrm{m}}$, the position of the neutral axis demonstrates initially nonlinear and finally linear rise. At the same time, the upper compressive zone decreases and the lower tensile zone increases gradually. When $R_{\mathrm{m}}$ is large enough, the minor compressive zone will be present at the bottom of the AC layer, and the second neutral axis also appears there. Specifically, along the driving and transverse direction, the compressive zone will appear at the bottom of the AC layer when $R_{\mathrm{m}}$ is 3 and 2.5, respectively. Furthermore, after the compressive zone is established at the bottom of AC layer, the size of the tensile zone within the AC layer does not change much when $R_{\mathrm{m}}$ continues increasing, which at remains at about $147 \mathrm{~mm}$. By comparing both horizontal directions, it could be found that under the same $R_{\mathrm{m}}$, the first neutral axis along the transverse direction is higher than that along the driving direction, that is, the compressive zone along the transverse direction is smaller than that along the driving direction.

In the previous pavement structure design, the AC layer was divided into several sub-layers to perform their respective functions based mainly on experience. Generally, the upper sublayer was applied to reduce permanent deformation, while the lower
Influence of Modulus

of Base Layer

on the Strain

Distribution

for Asphalt

Pavement 
(a)

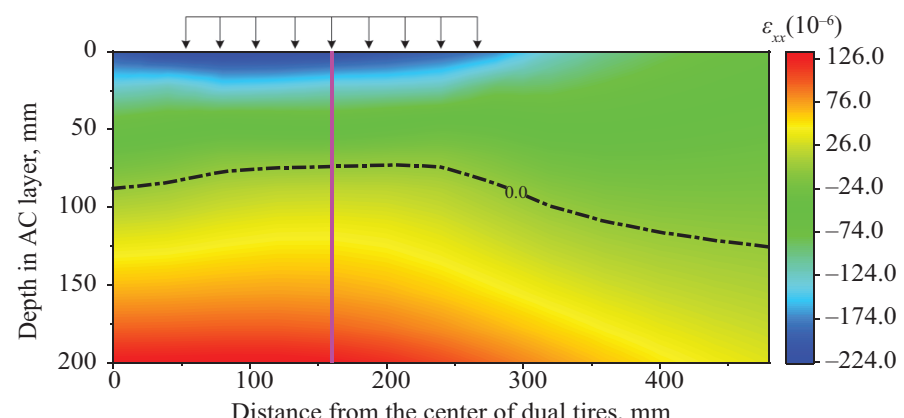

Distance from the center of dual tires, $\mathrm{mm}$

(b)

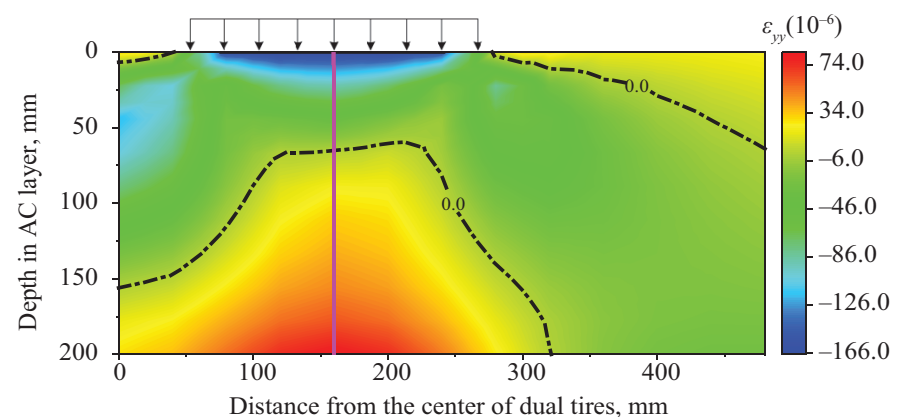

(c)
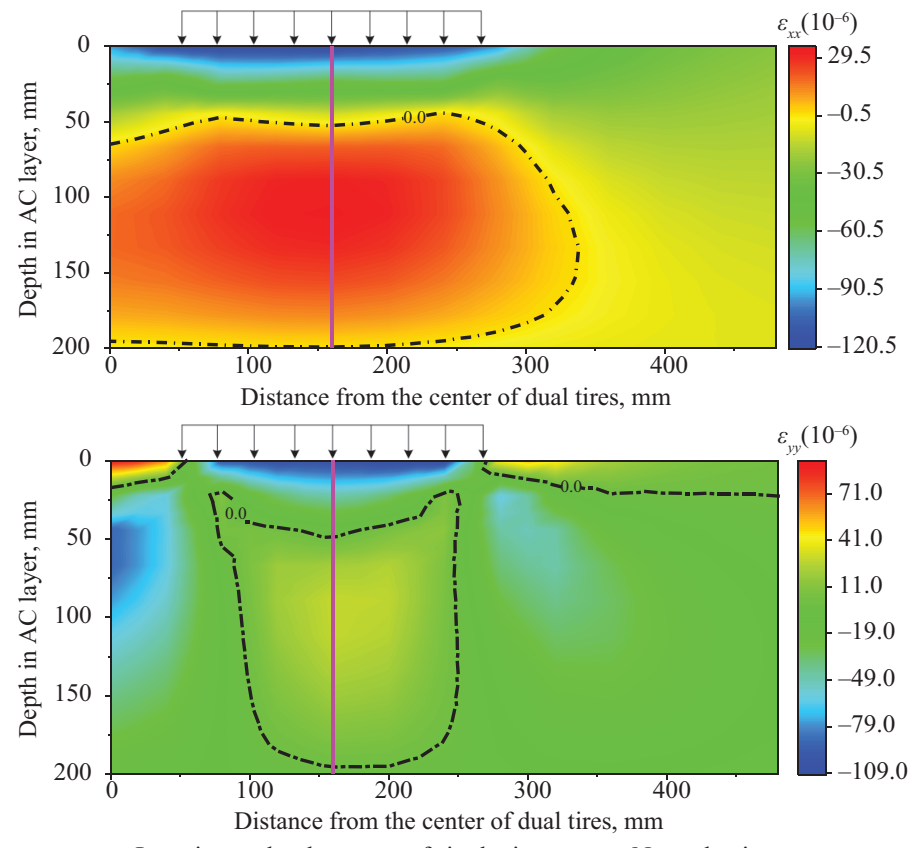

- Location under the center of single tire $\quad$-.- Neutral axis

Figure 8. Contour of strains in the AC layer: (a) along the driving direction with $R_{\mathrm{m}}=0.25$; (b) along the transverse direction with $R_{\mathrm{m}}=0.25$; (c) along the driving direction with $R_{\mathrm{m}}=3$; (d) along the transverse direction with $R_{\mathrm{m}}=3$ 
(a)

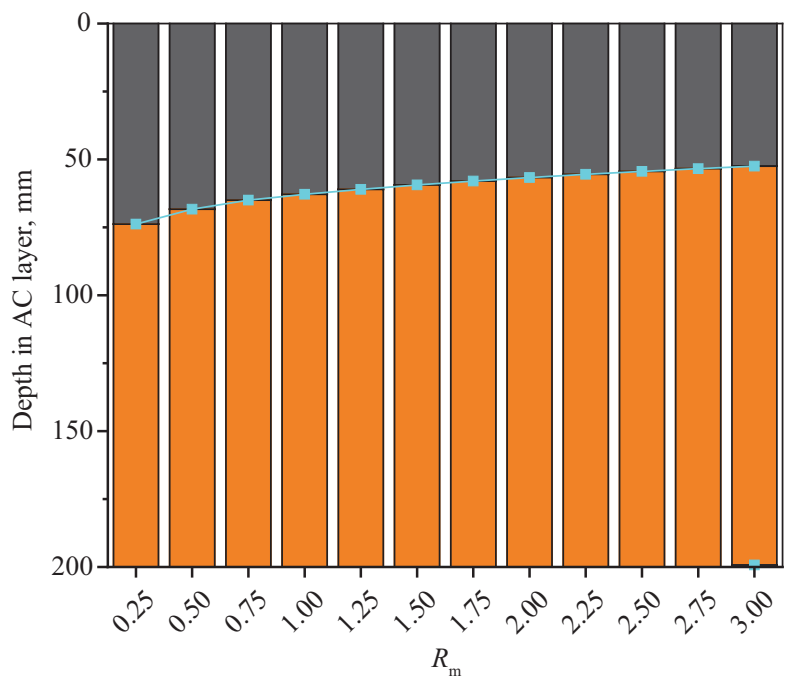

Kang Yao,

Xin Jiang, Jin Jiang,

Zhonghao Yang,

Yanjun Qiu

Influence of Modulus

of Base Layer

on the Strain

Distribution

for Asphalt

Pavement

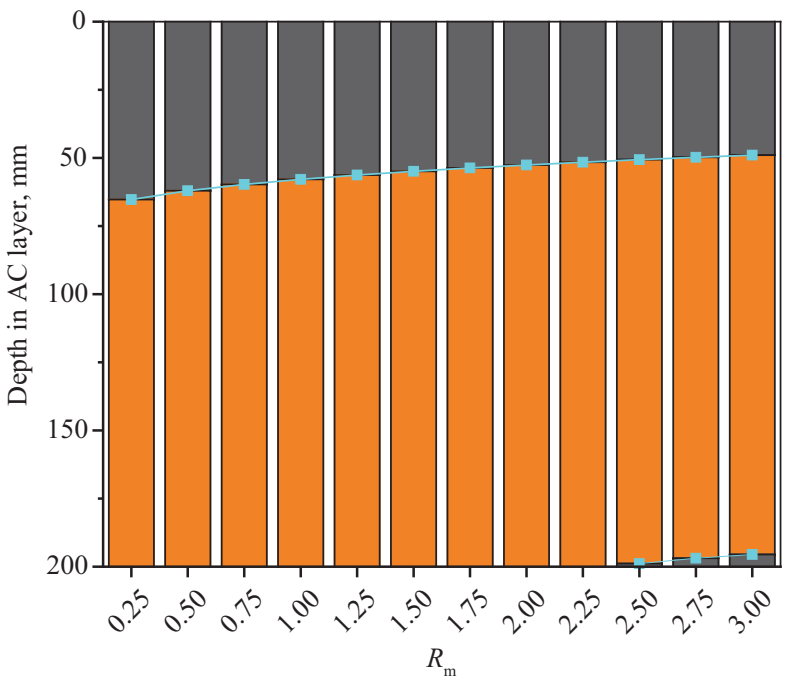

$\square$ Compressive zone

Tensile zone

- Neutral axis

Figure 9. Tensile, compressive zone and the neutral axis in the AC layer:

(a) along the driving direction; (b) along the transverse direction

sub-layer was implemented to prevent fatigue cracking. However, this experiential method can be improved based on the results of this study. According to the results obtained, the sub-layer used to avoid fatigue cracking should be rationally placed at the tensile zone in the AC layer. Specifically, when the modulus of the base layer is sufficiently large, the tensile zone develops in the middle part of the 
AC layer, which would induce initial cracking in this zone instead of the bottom of the AC layer. Therefore, the middle sub-layer needs to be carefully designed to improve its resistance to fatigue cracking, as well as permanent deformation, in this case.

\subsection{The average vertical compressive strains in the AC layer}

The average vertical compressive strain of the AC layer is used to predict its permanent deformation (Applied Research Associates, Inc., 2004a), thus, the average vertical compressive strain under different $R_{\mathrm{m}}$ in the whole AC layer, instead of under the center of one of the dual tires, is discussed in this paper. Figure 10 shows that the average vertical compressive strain in the AC layer will significantly enlarge with the increase of $R_{\mathrm{m}}$, which indicates that the large modulus of the base layer will make the resistance of permanent deformation of the AC layer decline. This happens because the base layer with large modulus limits deformation occurring at the bottom of the AC layer, but the upper part of the layer is still affected by the load, which makes the AC layer maintain the condition with high compressive stress. Therefore, in order to effectively control the permanent deformation of the AC layer, the modulus of the base layer could be reasonably reduced without increasing the permanent deformation of the subgrade.

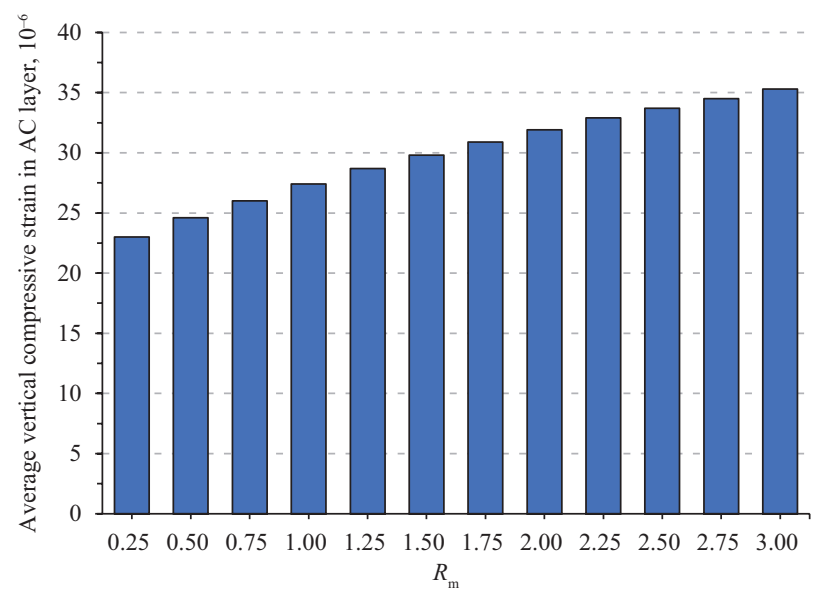

Figure 10. The average vertical compressive strain in the AC layer 
Kang Yao,

Xin Jiang, Jin Jiang,

Zhonghao Yang,

Yanjun Qiv

\section{Validation of macroscopic conclusions obtained from numerical simulation}

Influence of Modulus

of Base Layer

on the Strain

Distribution

for Asphalt

Pavement

Various types of the base layer were considered in this study, so it is very difficult, almost impossible to validate the above results by field measurements under the exactly same conditions. Therefore, the

(a)

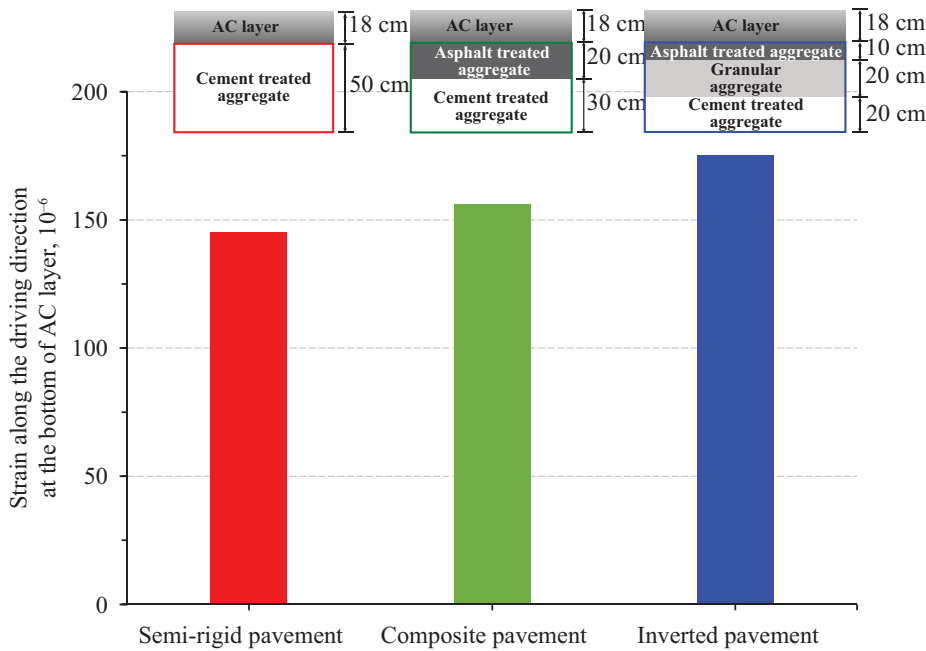

$$
\begin{aligned}
& \text { Measured tire-pavement contact pressure (MCP) } \\
& \text { Conventional tire-pavement contact pressure (CCP) }
\end{aligned}
$$

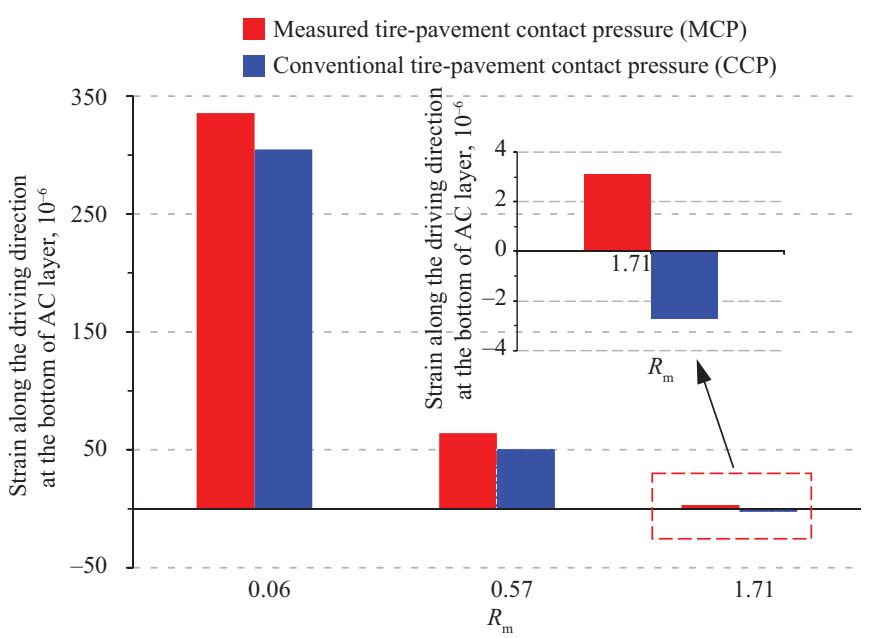

(b)

Figure 11. Strain along the driving direction at the bottom of the AC layer: (a) from field measurement presented in Wu et al. (2017); (b) from numerical simulation presented in Yue \& Svec (1995) 
correctness of the macroscopic conclusions and results obtained in this paper are confirmed by comparing them with some specific cases from the previous studies.

Based on the field measurement, Wu et al. (2017) measured the strain along the driving direction at the bottom of the AC layer of three field test sections constructed in Chengdu-Deyang-Nanchong Expressway in China, which was produced by the truck with a vehicle speed of $20 \mathrm{~km} / \mathrm{h}$ and single rear axis of $14 \mathrm{t}$, as shown in Figure 11(a). Three types of pavement structures have different base layer with the same AC layer and subgrade, and the sequence based on pavement stiffness is semi-rigid pavement > composite pavement > inverted pavement. Figure 11(a) demonstrates that the lower strain would be present in the pavement structure with higher modulus of the base layer, which agrees with the macroscopic conclusions obtained in the course of the numerical analysis.

Using numerical simulation, Yue \& Svec (1995) calculated the strain along the driving direction at the bottom of the AC layer of three pavement structures under different loads, as shown in Figure 11(b). $R_{\mathrm{m}}$ of three pavement structures is $0.06,0.57,1.71$, respectively. It could be seen from Figure 11 (b) that the strain would decrease with the increase of $R_{\mathrm{m}}$, and the compressive strain would be present even at a larger $R_{\mathrm{m}}$. This phenomenon is also consistent with the results acquired in this study.

Therefore, it can be concluded that the macroscopic conclusions and results reported in this paper agree with the available data from the previous research conducted by field tests and numerical simulations.

\section{Conclusions}

When $R_{\mathrm{m}}$ is small, the horizontal compressive strain appears in the upper part of the AC layer and diminishes along the depth. Then, the compressive strain converts into the tensile strain in the middle of the $\mathrm{AC}$ layer, and the value of the tensile strain increases along the depth. With the increase of $R_{\mathrm{m}}$, the increased rate of the tensile strain along the depth will become slow. Moreover, the value of the tensile strain decreases also along the depth when the $R_{\mathrm{m}}$ is sufficiently large.

The maximum tensile strain along the driving direction is always greater than that along the transverse direction in the AC layer, which is independent of $R_{\mathrm{m}}$. The maximum tensile strain in the AC layer initially 
could be reduced with the rise of $R_{\mathrm{m}}$, but when the value of $R_{\mathrm{m}}$ is greater than 1 , the tensile strain will increase slightly. In addition, amplifying $R_{\mathrm{m}}$, the maximum tensile strain in the AC layer does not necessarily occur at the bottom, but gradually rises to the middle. The depth of the maximum strain along the transverse direction rises faster than that along the driving direction.

The tensile strain at the bottom of the AC layer will decrease with the increase of $R_{\mathrm{m}}$, but the rate of decrease will gradually slow down. Finally, compressive strain occurs even at the bottom of the AC layer. And, when $R_{\mathrm{m}}$ is greater than or equal to one, there is a certain difference between the bottom and maximum strain, which will grow along with the increase of $R_{\mathrm{m}}$.

The upper part of the AC layer is compressive in both horizontal directions, the lower part of the AC layer is tensile, and the neutral axis is located at $50 \sim 80 \mathrm{~mm}$ away from the surface of pavement structure. With the increase of $R_{\mathrm{m}}$, the position of the neutral axis demonstrates initially nonlinear and finally linear rise. When $R_{\mathrm{m}}$ is large enough, the minor compressive zone will be present at the bottom of the AC layer, the second neutral axis also appears here. Furthermore, the size of the tensile zone within the AC layer remains at about $147 \mathrm{~mm}$ after the compression zone develops at the bottom of AC layer. Under the same $R_{\mathrm{m}}$, the first neutral axis along the transverse direction is higher than that along the driving direction, that is, the compressive zone along the transverse direction is smaller than that along the driving direction.

The vertical compressive strain in the AC layer initially increases and finally decreases along the depth of the AC layer, and its maximum value is located at about $55 \mathrm{~mm}$ down from the surface of the pavement structure. In addition, the average vertical compressive strain in the AC layer will significantly grow along with the increase of $R_{\mathrm{m}}$.

\section{Funding}

The research was supported by Sichuan Science and Technology Program (Grant No. 2019YFS0492).

\section{Conflicts of interest}

The authors declare that there are no conflicts of interest.
Influence of Modulus

of Base Layer

on the Strain

Distribution

for Asphalt

Pavement 


\section{REFERENCES}

Aarabi, S. \& Tabatabaei, S. A. (2018). Viscoelastic analysis of thickness variation of asphaltic pavements under repeated loading using finite element method. International Journal of Pavement Engineering, 21(2), 203-214. https://doi.org/10.1080/10298436.2018.1450504

AASHTO (1993). Guide for Design of Pavement Structures. Washington DC, United States: American Association of State Highway, Transportation Officials.

Abdelfattah, H. F. H., Al-Shamsi, K., \& Al-Jabri, K. (2018). Evaluation of rutting potential for asphalt concrete mixes containing copper slag. International Journal of Pavement Engineering, 19(7), 630-640. https://doi.org/10.1080/10298436.2016.1199875

Abu Al-Rub, R. K., Darabi, M. K., Huang, C. W., Masad, E. A., \& Little, D. N. (2012). Comparing finite element and constitutive modelling techniques for predicting rutting of asphalt pavements. International Journal of Pavement Engineering, 13(4), 322-338.

https://doi.org/10.1080/10298436.2011.566613

Al-Hadidy, A. I. \& Tan, Y. Q. (2009). Mechanistic analysis of ST and SBS-modified flexible pavements. Construction and Building Materials, 23(8), 2941-2950. https://doi.org/10.1016/j.conbuildmat.2009.02.023

Al-Qadi, I., Wang, H., Yoo, J., \& Dessouky, S. (2008). Dynamic analysis and in situ validation of perpetual pavement response to vehicular loading. Transportation Research Record: Journal of the Transportation Research Board, 2087, 29-39. https://doi.org/10.3141/2087-04

Applied Research Associates, Inc. (2004a). ERES Division. Design of New and Reconstructed Flexible Pavements. Chapter Three. NCHRP final document. Transportation Research Board of the National Academies, Washington, D.C.

Applied Research Associates, Inc. (2004b). ERES Division. Finite Element Procedures for Flexible Pavement Analysis. Appendix RR. NCHRP final document. Transportation Research Board of the National Academies, Washington, D.C..

Arshad, M. (2018). Correlation between resilient modulus $\left(M_{R}\right)$ and constrained modulus $\left(\mathrm{M}_{\mathrm{C}}\right)$ values of granular materials. Construction \& Building Materials, 159, 440-450. https://doi.org/10.1016/j.conbuildmat.2017.10.047

Arulrajah, A., Disfani, M. M., Haghighi, H., Mohammadinia, A., \& Horpibulsuk, S. (2015). Modulus of rupture evaluation of cement stabilized recycled glass/ recycled concrete aggregate blends. Construction and Building Materials, 84, 146-155. https://doi.org/10.1016/j.conbuildmat.2015.03.048

Austroads (2017). Guide to Pavement Technology - Part 2: Pavement Structural Design. Sydney, Australia: Austroads.

Bassim, R., \& Issa, M. (2020). Dynamic- and static-elastic moduli and strength properties of early-age Portland cement concrete pavement mixtures. Journal of Materials in Civil Engineering, 32(5), 04020066. https://doi.org/10.1061/(ASCE)MT.1943-5533.0003089

Benedetto, H. D., Roche, C. D. L., Baaj, H., Pronk, A., \& Lundström, R. (2004). Fatigue of bituminous mixtures. Materials \& Structures, 37, 202-216. https://doi.org/10.1007/BF02481620 
Bestgen, J. O., Hatipoglu, M., Cetin, B., \& Aydilek, A. H. (2016). Mechanical and environmental suitability of recycled concrete aggregate as a highway base material. Journal of Materials in Civil Engineering, 28(9), 04016067. https://doi.org/10.1061/(ASCE)MT.1943-5533.0001564

Bilodeau, J. P., \& Doré, G. (2012). Relating resilient behaviour of compacted unbound base granular materials to matrix and interlock characteristics. Construction and Building Materials, 37, 220-228. https://doi.org/10.1016/j.conbuildmat.2012.07.036

Bitumen Business Group (1998). BISAR 3.0 User Manual. Bitumen Business Group.

Brown, E. \& Foo, K. (1991). Evaluation of variability in resilient modulus test results (ASTM D 4123). Journal of Testing and Evaluation, 19(1), 1-13. https://doi.org/10.1520/JTE12523J

Camargo, F., (2008). Strength and stiffness of recycled base materials with and without fly ash. Thesis (MS). Madison, WI: University of Wisconsin-Madison.

Cetin, B., Aydilek, A. H., \& Guney, Y. (2010). Stabilization of recycled base materials with high carbon fly ash. Resources, Conservation and Recycling, 54, 878-892. https://doi.org/10.1016/j.resconrec.2010.01.007

Clapp, J. D. (2007). Analysis of rutting development in flexible pavements with geogrid-reinforced base layers using 3D finite element analysis. Thesis (MS), University of Maine, Orono, ME.

Collop, A. C. \& Cebon, D. (1995). A model of whole-life flexible pavement performance. Proceedings of the Institution of Mechanical Engineers, Part C: Journal of Mechanical Engineering Science, 209(6), 389-407. https://doi.org/10.1243/PIME_PROC_1995_209_170_02

Collop, A. C. \& Cebon, D. (1996). Stiffness reductions of flexible pavements due to cumulative fatigue damage. Journal of Transportation Engineering, 122(2), 131-139. https://doi.org/10.1061/(ASCE)0733-947X(1996)122:2(131)

Cortes, D. D., Shin, H., \& Santamarina, J. C. (2012). Numerical simulation of inverted pavement systems. Journal of Transportation Engineering, 138(12), 1507-1519. https://doi.org/10.1061/(ASCE)TE.1943-5436.0000472

Corté, J. \& Goux, M. (1996). Design of Pavement Structures: The French Technical Guide. Transportation Research Record Journal of the Transportation Research Board, 1539, 116-124. https://doi.org/10.1177/0361198196153900116

Davids, W. G. (2009). EverStressFE 1.0 software for 3D finite-element analysis of flexible pavement structures. University of Maine.

Fakhri, M. \& Ghanizadeh, A. R. (2014). An experimental study on the effect of loading history parameters on the resilient modulus of conventional and SBS-modified asphalt mixes. Construction and Building Materials, 53, 284-293. https://doi.org/10.1016/j.conbuildmat.2013.11.091

Francois, A., Ali, A. \& Mehta, Y. (2019). Evaluating the impact of different types of stabilised bases on the overall performance of flexible pavements. International Journal of Pavement Engineering, 20(8), 938-946.

https://doi.org/10.1080/10298436.2017.1366766
Influence of Modulus of Base Layer on the Strain Distribution for Asphalt Pavement 
Henry, K. S., Clapp, J., Davids, W., Humphrey, D., \& Barna, L. (2009). Structural improvements of flexible pavements using geosynthetics for base course reinforcement. U.S. Army Corps of Engineers, Engineer Research and Development Center, Cold Regions Research and Engineering Laboratory, Hanover, NH.

Hu, X., \& Walubita, L. F. (2011). Effects of layer interfacial bonding conditions on the mechanistic responses in asphalt pavements. Journal of Transportation Engineering, 137(1), 28-36. https://doi.org/10.1061/(ASCE)TE.1943-5436.0000184

Huang, C. W., Abu Al-Rub, R. K., Masad, E. A., \& Little, D. N. (2011). Three-dimensional simulations of asphalt pavement permanent deformation using a nonlinear viscoelastic and viscoplastic model. Journal of Materials in Civil Engineering, 23(1), 56-68.

https://doi.org/10.1061/(ASCE)MT.1943-5533.0000022

Huang, X. (2017). Road Subgrade and Pavement Engineering $5^{\text {th }}$ Edition. China Communication Press Co., Ltd.

Huang, Y. H. (2004). Pavement Analysis and Design $2^{\text {nd }}$ Edition. Prentice Hall.

IRC (2012). Guidelines for the Design of Flexible Pavements. 3rd ed. Indian Road Congress.

Ji, X., Hou, Y., Li, X., \& Wang, T. (2018). Comparison on properties of cement-stabilised gravel prepared by different laboratory compaction methods. Road Materials and Pavement Design, 20(4), 991-1003. https://doi.org/10.1080/14680629.2017.1423105

Jiang, X., Zeng, C., Gao, X., Liu, Z., \& Qiu, Y. (2019). 3D FEM analysis of flexible base asphalt pavement structure under non-uniform tyre contact pressure. International Journal of Pavement Engineering, 20(9), 999-1011. https://doi.org/10.1080/10298436.2017.1380803

Jiang, X., Zeng, C., Yao, K., Gu, H., Li, Z., \& Qiu, Y. (2021). Influence of bonding conditions on flexible base asphalt pavement under non-uniform vertical loads. International Journal of Pavement Engineering, 22(12), 1491-1503. https://doi.org/10.1080/10298436.2019.1697441

Jiang, Y. J. \& Fan, L. F. (2013). An investigation of mechanical behavior of cement-stabilized crushed rock material using different compaction methods. Construction and Building Materials, 48, 508-515.

https://doi.org/10.1016/j.conbuildmat.2013.07.017

Lavasani, M., Latifi N. M., \& Fartash, H. (2015). Experimental investigation on mineral and organic fibers effect on resilient modulus and dynamic creep of stone matrix asphalt and continuous graded mixtures in three temperature levels. Construction and Building Materials, 95, 232-242.

https://doi.org/10.1016/j.conbuildmat.2015.07.146

Leite, F. C., Motta, R. S., Vasconcelos, K. L., \& Bernucci, L. (2011). Laboratory evaluation of recycled construction and demolition waste for pavements. Construction and Building Materials, 25, 2972-2979. https://doi.org/10.1016/j.conbuildmat.2010.11.105

Li, J., White, D. J., Stephenson, W. R., \& Li, C. (2019). Considerations for laboratory resilient modulus testing of unbound pavement base materials. Construction and Building Materials, 195, 515-523.

https://doi.org/10.1016/j.conbuildmat.2018.11.049 
Li, S. \& Hao, P. (2020). Stress dependent and redistribution behaviour of Yanjun Qiu unbound granular material. International Journal of Pavement Engineering, 21(3), 347-356. https://doi.org/10.1080/10298436.2018.1475667

Liu, Q. \& Shalaby, A. (2013). Simulation of pavement response to tire pressure and shape of contact area. Canadian Journal of Civil Engineering, 40(3), 236-242. https://doi.org/10.1139/cjce-2011-0567

Lv, S., Wang, X., Liu, C., \& Wang, S., (2018). Fatigue damage characteristics considering the difference of tensile-compression modulus for asphalt mixture. Journal of Testing and Evaluation, 46(6), 2470-2482. https://doi.org/10.1520/JTE20170114

Lv, S., Yuan, J., Liu, C., Wang, J., Li, J., \& Zheng, J. (2019). Investigation of the fatigue modulus decay in cement stabilized base material by considering the difference between compressive and tensile modulus. Construction and Building Materials, 223, 491-502. https://doi.org/10.1016/j.conbuildmat.2019.07.003

Maina, J. W., Ozawa, Y. \& Matsui, K. (2012). Linear elastic analysis of pavement structure under non-circular loading. Road Materials and Pavement Design, 13(3), 403-421. https://doi.org/10.1080/14680629.2012.705419

Miao, Y., Huang, Y., Zhang, Q., \& Wang, L. (2016). Effect of temperature on resilient modulus and shear strength of unbound granular materials containing fine RAP. Construction and Building Materials, 124, 1132-1141. https://doi.org/10.1016/j.conbuildmat.2016.08.137

Ministry of Transport of China (2006). Specifications for Design of Highway Asphalt Pavement. China Communications Press.

Mohammad, L. N., Raghavandra, A., \& Huang, B. (2000). Laboratory performance evaluation of cement-stabilized soil base mixtures. Transportation Research Record: Journal of the Transportation Research Board, 1721, 19-28. https://doi.org/10.3141/1721-03

Park, S. W. \& Lytton R. L. (2004). Effect of stress-dependent modulus and poisson's ratio on structural responses in thin asphalt pavements. Journal of Transportation Engineering, 130(3), 387-394. https://doi.org/10.1061/(ASCE)0733-947X(2004)130:3(387)

Romeo, E., Orazi, M., Orazi, U. S., Accardo, C., Noto, S., \& Tebaldi, G. (2019). Evaluation of "long-term behaviour under traffic" of cement treated mixture with RAP. Construction and Building Materials, 208, 421-426. https://doi.org/10.1016/j.conbuildmat.2019.03.045

Saad, B., Mitri, H. \& Poorooshasb, H. (2006). 3D FE Analysis of flexible pavement with geosynthetic reinforcement. Journal of Transportation Engineering, 2006, 132(5), 402-415. https://doi.org/10.1061/(ASCE)0733-947X(2006)132:5(402)

Schwartz, C. W., Li, R., Ceylan, H., Kim, S., \& Gopalakrishnan, K. (2013). Global sensitivity analysis of mechanistic-empirical performance predictions for flexible pavements. Transportation Research Record: Journal of the Transportation Research Board, 2368(1), 12-23.

https://doi.org/10.3141/2368-02 
Shafabakhsh, G. \& Tanakizadeh, A. (2016). Evaluation of resilient behavior of flexible pavement asphalt layers. Materials and Structures, 49(7), 2829-2840. https://doi.org/10.1617/s11527-015-0689-0

Solanki, P., Khoury, N., \& Zaman, M. M. (2009). Engineering properties and moisture susceptibility of silty clay stabilized with lime, class C Fly Ash, and Cement Kiln Dust. Journal of Materials in Civil Engineering, 21(12), 749-757. https://doi.org/10.1061/(ASCE)0899-1561(2009)21:12(749)

Venudharan, V. \& Biligiri, K. P. (2015). Estimation of phase angles of asphalt mixtures using resilient modulus test. Construction and Building Materials, 82, 274-286. https://doi.org/10.1016/j.conbuildmat.2015.02.061

Wu, Y., Jiang, X., Liang, X. J., \& Feng, W. Q. (2017). Mechanical behaviours of typical asphalt pavement structures under wheel loads. Journal of Southwest Jiaotong University, 52(3), 563-570.

Xiao, Y., Tutumluer, E., \& Siekmeier, J. (2011). Mechanistic-empirical evaluation of aggregate base and granular subbase quality affecting flexible pavement performance in minnesota. Transportation Research Record Journal of the Transportation Research Board, 2227, 97-106. https://doi.org/10.3141/2227-11

Yue, Z. Q. \& Svec, O. J. (1995). Effect of tire-pavement contact pressure distribution on the response of asphalt concrete pavements. Canadian Journal of Civil Engineering, 22, 849-860. https://doi.org/10.1139/195-103 